\title{
Coordinated prophylactic surgical management for women with hereditary breast-ovarian cancer syndrome
}

\author{
Larissa I Batista ${ }^{1}$, Karen H Lu${ }^{2}$, Elisabeth $\mathrm{K} \mathrm{Beahm}^{3}$, Banu K Arun ${ }^{4}$, \\ Diane C Bodurka ${ }^{2}$ and Funda Meric-Bernstam*1
}

\begin{abstract}
Address: ${ }^{1}$ Department of Surgical Oncology, The University of Texas M. D. Anderson Cancer Center, Houston, TX, USA, ${ }^{2}$ Department of Gynecologic Oncology, The University of Texas M. D. Anderson Cancer Center, Houston, TX, USA, ${ }^{3}$ Department of Plastic Surgery, The University of Texas M. D. Anderson Cancer Center, Houston, TX, USA and ${ }^{4}$ Department of Breast Medical Oncology, The University of Texas M. D. Anderson Cancer Center, Houston, TX, USA

Email: Larissa I Batista - lara.rs@terra.com.br; Karen H Lu - khlu@mdanderson.org; Elisabeth K Beahm - ebeahm@mdanderson.org; Banu K Arun - barun@mdanderson.org; Diane C Bodurka -dcbodurka@mdanderson.org; Funda Meric-Bernstam* -fmeric@mdanderson.org

* Corresponding author
\end{abstract}

Published: 14 April 2008

BMC Cancer 2008, 8:101 doi:10.1186/1471-2407-8-101
Received: 19 October 2007

Accepted: 14 April 2008

This article is available from: http://www.biomedcentral.com/I47I-2407/8/I0I

(C) 2008 Batista et al; licensee BioMed Central Ltd.

This is an Open Access article distributed under the terms of the Creative Commons Attribution License (http://creativecommons.org/licenses/by/2.0), which permits unrestricted use, distribution, and reproduction in any medium, provided the original work is properly cited.

\begin{abstract}
Background: Women with BRCAI or BRCA2 mutations have a substantially increased risk of breast and ovarian cancer compared with the general population. Therefore, prophylactic mastectomy (PM) and bilateral salpingo-oophorectomy (BSO) have been proposed as riskreduction strategies for BRCAI/2 mutation carriers. We aimed to assess the feasibility of coordinated PM and BSO in hereditary breast-ovarian cancer syndrome.
\end{abstract}

Methods: High risk women for breast and ovarian cancer who underwent coordinated PM and BSO were included in this study. Clinical characteristics and surgical and oncologic outcomes were retrospectively reviewed.

Results: Twelve patients underwent coordinated PM and BSO. Ten had history of previous breast cancer. Autologous breast reconstruction was performed in ten patients. The mean age at surgery was 43 (range 34-65). Mean operating time was 9.3 hours (range 3-16) with a mean postoperative hospitalization of 5.4 days (range 4-8). Intraoperatively, there were no major surgical complications. Postoperatively, one patient developed an abdominal wound dehiscence, another reoperation for flap congestion; one had umbilical superficial epidermolysis, and one patient developed aspiration pneumonia. At a mean follow-up of 84 months, 10 of patients were cancerfree. Although no patients developed a new primary cancer, two developed a distant recurrence.

Conclusion: Coordinated PM and BSO is a feasible procedure with acceptable morbidity in selected high-risk patients that desire to undergo surgery at one operative setting.

\section{Background}

Women with BRCA1 or BRCA2 mutation have a substantially increased risk of breast and ovarian cancer compared with the general population [1]. Breast cancer due to a hereditary cause is about 5 to $10 \%$ of all malignant breast disease and 25 to $40 \%$ of breast cancers that occur in women younger than 35 years old. Cumulative lifetime risk (to 70 years of age) for invasive breast cancer in 
women with BRCA1 and BRCA2 mutation is 40 to $85 \%$ and for invasive epithelial ovarian cancer is 15 to $65 \%$ [14]. Women who are BRCA1/2 mutation carriers also have a $26-40 \%$ risk of contralateral breast cancer in 10 years $[5,6]$.

Currently, management strategies for high-risk women include intense clinical follow up (every 3-6 months clinical breast exams and annual breast magnetic resonance imaging starting at 25 years of age, as well as gynecologic cancer screening with twice-yearly transvaginal ultrasound and serum CA-125) [7] and chemoprevention with tamoxifen $[8,9]$. A more aggressive risk reduction approach is PM and BSO. Prophylactic surgery has been shown to be very effective in significantly reducing breast and ovarian cancer occurrence [10-12]. This report describes the feasibility of coordinated PM and BSO in women at high risk for breast-ovarian cancer.

\section{Methods}

\section{Patient selection}

Patients who underwent PM and BSO in the same operation were identified through search of databases maintained by the Department of Medical Informatics and the Department of Gynecologic Oncology. This study was approved by the University of Texas M. D. Anderson Cancer Center Institutional Review Board.

\section{Surgical technique}

The indications for PM and BSO, and other management options were discussed with each patient. Risks, complications and alternatives were discussed and informed consent was obtained. All patients underwent PM and BSO. The patients who were evaluated and were felt to be good candidates for autologous bilateral breast reconstruction from the lower abdominal wall underwent bilateral flap reconstruction of the breast using the transverse rectus abdominus myocutaneous (TRAM) flaps or deep inferior epigastric perforator (DIEP) flaps, and the prophylactic surgeries simultaneously. Patients who did not undergo breast reconstruction had their gynecologic procedure and mastectomy at the same time.

Patients were administered general anesthesia. The breasts and the abdomen were then prepared and draped in the usual manner for exposure of the anterior chest and abdomen. Markings were made along the breast by the reconstructive and breast surgery services. The breast surgical oncology team performed the mastectomy while the abdominal flaps were harvested and transferred by the reconstructive team simultaneously. After that the abdominal flap was inset into the recipient site and revascularized if a free flap was performed. The flaps were temporarily inset and secured to the chest wall while the gynecologic oncology service performed the BSO. The gynecologic team performed the BSO and in some cases, also a total abdominal hysterectomy (TAH). The peritoneum was closed by the gynecologic surgeons and at this point the additional portion of the abdominal closure was carefully performed by the reconstructive team.

\section{Data Collection and Statistics}

Medical records were retrospectively reviewed, and clinical, demographic and genetic characteristics were abstracted. Surgical procedures, operating times, complications and subsequent clinical follow up were also recorded. For patients who had a personal history of previous breast cancer, we also collected data related to disease characteristics and follow up. The results are described as average, standard deviation and percentage.

\section{Results}

From June 1996 to July 2003, twelve high-risk women had coordinated PM and BSO. The mean age at prophylactic surgery was 43 years (range 34-65). The clinical characteristics of the patients are described in Table 1 . Eleven of the patients had undergone BRCA testing and were known to have a deleterious mutation. Ten patients had a personal history of breast cancer prior to the prophylactic surgery. Nine patients received chemotherapy, and six received radiation therapy.

Table I: Clinical Characteristics $(n=12)$

\begin{tabular}{lc}
\hline Characteristics & Number (\%) \\
\hline Mean age at prophylactic surgery (range) & $43(34-65)$ \\
BMI (SD) & $22.7 \pm 3.1 *$ \\
Race & \\
White, Non-Ashkenazie Jewish & $10(83.3)$ \\
Ashkenazie Jewish & $1(8.3)$ \\
Hispanic & $1(8.3)$ \\
Personal previous history of breast cancer & $10(83.3)$ \\
$\quad$ Primary & $9(75)$ \\
Primary with local recurrence & $1(8.3)$ \\
Personal history of ovarian cancer & $0(0)$ \\
Family history of breast cancer & $11(91.6)$ \\
First degree relatives with breast cancer & $9(75)$ \\
Family history of ovarian cancer & $2(16.6)$ \\
First degree relatives with ovarian cancer & $1(8.3)$ \\
Smoking & $2(16.66)$ \\
Parity & \\
I live birth & $2(16.66)$ \\
2 live birth & $7(58.33)$ \\
3 live birth & $3(25)$ \\
Menopausal Status & \\
Premenopausal & $7(58.33)$ \\
Postmenopausal & $5(4 I .66)$ \\
Due to chemotherapy & $1(8.33)$ \\
Due to use of tamoxifen & $1(8.33)$ \\
Due to previous hysterectomy & $2(16.66)$ \\
Natural menopause & $1(8.33)$ \\
\hline
\end{tabular}

*Values are presented as average \pm standard deviation 
During the prophylactic surgeries, breast and gynecologic surgeries were performed at the same operation. Six patients underwent contralateral mastectomy, four therapeutic/completion mastectomies in addition to the prophylactic contralateral mastectomies and two underwent bilateral prophylactic mastectomy. All patients underwent open BSO and seven also underwent a total abdominal hysterectomy (TAH). Ten patients underwent bilateral reconstruction, nine with TRAM flap and one with DIEP flap. The indication and technical details of the coordinated surgical prophylactic and complementary procedures are detailed in Table 2 .

The mean operating time was 9.3 hours (range $3-16$ ) with a hospital stay of 5.4 days (range $4-8$ ). There were no cases of death, bleeding requiring blood transfusion or other major complication during surgery.

The postoperative complications seen are listed in the Table 2. In one patient a large ventral hernia was found during the TRAM flap dissection, which was repaired with polyproprolene mesh at that time. Postoperatively, this patient had an abdominal wound dehiscence. The abdominal wall (fascia and mesh) remained intact. The wound was managed conservatively and completely closed about 1 month later with no further complications. A patient who underwent reconstruction with pedicle TRAM flaps, right delayed, left immediate had a reoperation for left flap congestion. A super-charge of left pedicle TRAM flap, artery and vein, was successfully performed.
Placement with bilateral saline-filled mammary implants was performed one year later due to a contour deformity of the superior pole of the breast mound. Another patient who had prophylactic contralateral mastectomy and TAHBSO followed by reconstruction of both breasts with bilateral free TRAM flap, had some superficial epidermolysis of her umbilicus postoperatively. This was managed conservatively, leaving a hypertrophic scar with no further complications. The development of aspiration pneumonia was seen postoperatively in one patient who underwent contralateral prophylactic mastectomy, TAH-BSO, and free TRAM reconstruction. This was treated aggressively with pulmonary physiotherapy and intravenous antibiotics. Otherwise, the postoperative course was uneventful. Even with those complications, all patients recovered well postoperatively. There were no complications directly attributable to the combination of the gynecologic and breast procedures.

At a mean follow-up was 84 months, none of the patients developed a new breast cancer. However, two patients died due to breast cancer metastasis; both patients had a breast cancer diagnosis at the time of their risk-reducing surgery. The first patient was diagnosed with breast cancer at 29 years of age with a clinical stage IIIA breast cancer. She underwent prophylactic contralateral mastectomy and BSO one year after the diagnosis. She was free of disease for 2 years when was found to have bone, lung and brain metastasis. She received palliative chemotherapy but died from breast cancer nine months later. The second

Table 2: Coordinated Surgical Procedures and Complications

\begin{tabular}{|c|c|c|c|c|c|}
\hline Patient & Previous Breast Cancer & Prophylactic Breast Surgery & $\begin{array}{c}\text { Prophylactic Gynecologic } \\
\text { Surgery }\end{array}$ & Reconstruction & Postoperative Complications \\
\hline I & yes & Contralateral mastectomy & BSO (previous TAH) & Free TRAM & None \\
\hline 2 & no & Bilateral mastectomy & TAH-BSO & Pedicle TRAM & None \\
\hline 3 & yes & Contralateral mastectomy & BSO (previous TAH) & no & None \\
\hline 4 & yes & Contralateral mastectomy & TAH-BSO & no & None \\
\hline 5 & yes & Contralateral mastectomy & BSO & Pedicle TRAM & $\begin{array}{c}\text { Reoperation for flap } \\
\text { congestion }\end{array}$ \\
\hline 6 & yes & Contralateral mastectomy & TAH-BSO & Free TRAM & $\begin{array}{l}\text { Superficial epidermolysis of } \\
\text { the umbilicus }\end{array}$ \\
\hline 7 & yes & $\begin{array}{c}\text { Contralateral + Completion } \\
\text { mastectomy }\end{array}$ & TAH-BSO & Free TRAM & None \\
\hline 8 & yes & Contralateral mastectomy & BSO & Free DIEP & None \\
\hline 9 & no & Bilateral mastectomy & TAH-BSO & Free TRAM & None \\
\hline 10 & yes & Contralateral mastectomy & TAH-BSO & Free TRAM & $\begin{array}{l}\text { Postoperative aspiration } \\
\text { pneumonia }\end{array}$ \\
\hline 11 & yes & $\begin{array}{c}\text { Contralateral + Completion } \\
\text { mastectomy }\end{array}$ & BSO (previous TAH) & Free TRAM & None \\
\hline 12 & yes & $\begin{array}{c}\text { Contralateral + Completion } \\
\text { mastectomy }\end{array}$ & TAH-BSO & Free TRAM & Abdominal wound dehiscence \\
\hline
\end{tabular}

BSO $=$ Bilateral salpingo-oophorectomy.

$\mathrm{TAH}=$ Total abdominal hysterectomy.

TRAM = Transverse rectus abdominus myocutaneous.

DIEP = Deep inferior epigastric perforator. 
one was 31 when was diagnosed with a Stage IIA breast cancer. She underwent prophylactic contralateral mastectomy and BSO about 2 years after the diagnosis. Ten months after prophylactic surgery, she was found to have metastatic disease to the brain. She received palliative chemotherapy and deceased four and a half years later. Both patients had undergone a negative staging work-up with a chest x-ray, bone scan and abdominal CT at their initial breast cancer diagnosis (11 and 15 months prior to prophylactic surgery). The remaining 10 patients did not have recurrence and are still alive.

\section{Discussion}

Several studies have shown that the risk of breast and ovarian cancer can be decreased by prophylactic surgery in carriers of BRCA mutations. Prophylactic BSO not only reduces the risk of ovarian cancer by $80-95 \%$ but also reduces the risk of contralateral breast cancer by $50 \%$ $[10,13]$. Rebbeck et al demonstrated that bilateral PM reduced the risk of breast cancer by $90 \%$ in women with intact ovaries and by $95 \%$ in women who underwent both PM and oophorectomy [12]. Our study aimed to evaluate the feasibility of coordinated prophylactic mastectomy and BSO in high risk breast-ovarian cancer women.

Women with breast cancer who carry deleterious BRCA mutations are at increased risk of developing a second primary breast cancer as well as a primary ovarian cancer [14]. However, the prevention of a second primary breast cancer by prophylactic mastectomy may be overshadowed by the prognosis of the first tumor. In a decision analysis, Schrag et al demonstrated that life expectancy gains from risk-reducing surgery is greatest for patients that are young, for high-penetrance mutations, and in node-negative disease [15]. The breast cancer-related deaths of two of the patients in our small series underscore the challenges of patient selection for risk-reducing procedures.

It is critical to discuss immediate breast reconstruction with all patients undergoing PM. Most patients undergoing bilateral PM for risk-reduction are candidates for reconstruction. Immediate reconstruction is also usually feasible in most patients undergoing a mastectomy for breast cancer, but may be deferred in patients in whom postmastectomy radiation therapy is planned $[16,17]$ Reconstructive options include implant-based reconstruction, as well as autologous reconstruction approaches such as pedicled TRAM flap, or free TRAM flap with various degrees of muscle sparing, the deep inferior epigastric artery perforator (DIEP) and the superficial inferior epigastric artery (SIEA) flap. Implant-based reconstruction is preferred by some due to ease of performance, while autologous tissue reconstruction is preferred by others due to its natural shape, soft consistency and long-lasting aesthetic results. The choice of reconstruction is an impor- tant determinant of operative time, and potential morbidity of the surgery. Most patients who elect contralateral prophylactic mastectomy (CPM) at our institution undergo autologous tissue reconstruction [18]. The choice of reconstruction is an important determinant of operative time, and potential morbidity of the surgery. At our institution, with the use of free TRAM flap reconstruction, flap complications have been observed in $24 \%$ of patients, and donor site complications in $15 \%$ of patients [19]. In this series, 10 of 12 patients underwent reconstruction with abdominal TRAM flaps, and even though the reconstruction increased the operative time, there were no major intraoperative or postoperative complications. The complications seen in this study are in line with our previous institutional experience with mastectomy and breast reconstruction [19]. Thus in this limited series, adding the gynecologic surgery to the breast procedure resulted in acceptable morbidity.

Although we did not have any substantial complications associated with the gynecologic surgery in our series, there is a potential risk in adding the gynecologic procedure to prophylactic surgery, especially in the setting of autologous reconstructive surgery. There is a small risk of intraabdominal bleeding, which could lead to a low flow state for the autologous flap, and in the case of a microvascular free flap, even to flap loss. Hysterectomy exposes the abdomen to vaginal bacterial flora and may also increase the risk of wound infections and other wound complications, a risk factor for infection and loss of tissueexpander/implant-based reconstruction. The magnitude of a bilateral autologous breast reconstruction is significant for both patient and surgeon, and the impact of flap loss, while rare (less than $2 \%$ in our institution), is profound. For gynecologic procedures, the patient is placed in Trendelenberg immediately after revascularization of the flap, the most vulnerable time period for vascular compromise. In addition, the flap can not be easily visualized at this time. There are accordant risks for flap avulsion or compromise of the vascular pedicle, especially in the newer perforator based flaps, such as the DIEP flap, which were developed to spare the abdominal donor site morbidity associated with increased muscle harvest of the rectus abdominis muscle, but leave the vascular pedicle much less protected. Additionally, there is need for careful closure of the abdominal donor site to prevent risk of herniation.

Coordinated single operation has three main advantages. The first is that it allows for a single operation and recovery, potentially enhancing patient convenience. The second is that oophorectomy may allow for the initiation of aromatase inhibitors for endocrine treatment in premenopausal patients with estrogen-receptor positive disease. The third is that it allows for early ovarian risk reduction, 
minimizing the theoretical risk of ovarian cancer development in between staged procedures. These advantages of a single operation should be weighed against potential morbidity of adding the gynecological surgery to the prophylactic mastectomy with reconstruction. As an alternative,

As breast reconstruction is a staged procedure involving a series of 2-3 procedures several months apart, the gynecologic procedure may be performed during one of the secondary reconstructive procedures.

In our series of patients, seven of nine patients who had a uterus at that time also underwent TAH during the procedure. No complications due to hysterectomy were seen. However, our group and others are moving away from performing hysterectomy routinely in these patients. In patients with uterine or cervical abnormalities, hysterectomy may be considered. In addition, women who have taken tamoxifen may consider hysterectomy due to the increased risk of endometrial cancer. However, patients need to be counseled that the addition of hysterectomy to bilateral oophorectomy may increase surgical time and morbidity [20].

Our study is limited as it is a small retrospective case series from a single institution. Further, our center has significant expertise in breast and gynecologic oncology as well as reconstructive surgery; this coordinated approach may be met with additional challenges, including higher rates of morbidity, when performed by lower volume surgical teams. Finally, due to our short clinical follow-up and small sample size, we are unable to report long-term risk reduction rates.

\section{Conclusion}

In conclusion, our study showed that coordinated PM and BSO is a feasible procedure with acceptable morbidity for patients at high risk for breast and ovarian cancer who elect to undergo synchronous risk-reduction operations. However, the optimal approach and timing for risk-reducing surgery in women at high-risk for breast-ovarian cancer needs to be determined in a multidisciplinary fashion, taking into account several factors including the time-line of greatest breast and gynecologic cancer risk and also the potential complications of the operations.

\section{Competing interests}

The author(s) declare that they have no competing interests.

\section{Authors' contributions}

LB was responsible for data collection data analysis and writing of the manuscript. KL was responsible for conception, data collection, data analysis and editing of the man- uscript. EB was responsible for assistance in data collection, data analysis and editing of the final manuscript. BA was responsible for editing the final manuscript. DB was responsible for conception and editing the final manuscript. FMB was responsible for conception, assistance in study design, final data analysis, writing and finalizing the manuscript. All authors have read and approved the final manuscript.

\section{Acknowledgements}

We thank Toi Clayton Soh for assistance with manuscript preparation.

\section{References}

I. Ford D, Easton DF, Stratton M, Narod S, Goldgar D, Devilee P, Bishop DT, Weber B, Lenoir G, Chang-Claude J, Sobol H, Teare MD, Struewing J, Arason A, Scherneck S, Peto J, Rebbeck TR, Tonin P, Neuhausen S, Barkardottir R, Eyfjord J, Lynch H, Ponder BA, Gayther SA, Zelada-Hedman M, et al.: Genetic heterogeneity and penetrance analysis of the BRCAI and BRCA2 genes in breast cancer families. The Breast Cancer Linkage Consortium. Am J Hum Genet 1998, 62(3):676-689.

2. Antoniou A, Pharoah PD, Narod S, Risch HA, Eyfjord JE, Hopper JL, Loman N, Olsson H, Johannsson O, Borg A, Pasini B, Radice P, Manoukian S, Eccles DM, Tang N, Olah E, Anton-Culver H, Warner E, Lubinski J, Gronwald J, Gorski B, Tulinius H, Thorlacius S, Eerola H, Nevanlinna H, Syrjakoski K, Kallioniemi OP, Thompson D, Evans C, Peto J, Lalloo F, Evans DG, Easton DF: Average risks of breast and ovarian cancer associated with BRCAI or BRCA2 mutations detected in case Series unselected for family history: a combined analysis of 22 studies. Am J Hum Genet 2003, 72(5): I I I7-I I 30.

3. Oros KK, Ghadirian P, Maugard CM, Perret C, Paredes Y, Mes-Masson AM, Foulkes WD, Provencher D, Tonin PN: Application of BRCAI and BRCA2 mutation carrier prediction models in breast and/or ovarian cancer families of French Canadian descent. Clin Genet 2006, 70(4):320-329.

4. Risch HA, McLaughlin JR, Cole DE, Rosen B, Bradley L, Fan I, Tang J, Li S, Zhang S, Shaw PA, Narod SA: Population BRCAI and BRCA2 mutation frequencies and cancer penetrances: a kincohort study in Ontario, Canada. J Natl Cancer Inst 2006, 98(23): I694- I 706.

5. Metcalfe K, Lynch HT, Ghadirian P, Tung N, Olivotto I, Warner E, Olopade OI, Eisen A, Weber B, McLennan J, Sun P, Foulkes WD, Narod SA: Contralateral breast cancer in BRCAI and BRCA2 mutation carriers. J Clin Oncol 2004, 22( I 2):2328-2335.

6. Pierce LJ, Levin AM, Rebbeck TR, Ben-David MA, Friedman E, Solin LJ, Harris EE, Gaffney DK, Haffty BG, Dawson LA, Narod SA, Olivotto IA, Eisen A, Whelan TJ, Olopade OI, Isaacs C, Merajver SD, Wong JS, Garber JE, Weber BL: Ten-year multi-institutional results of breast-conserving surgery and radiotherapy in BRCAI/2associated stage I/II breast cancer. J Clin Oncol 2006, 24( I 6):2437-2443.

7. National Comprehensive Cancer Network: Clinical Practice Guidelines in Oncology. Genetic/familial high risk assessment: breast and ovarian [http://www.ncen.org/professionals/ physician gls/pdf/genetics screening.pdf]

8. Cuzick J, Powles T, Veronesi U, Forbes J, Edwards R, Ashley S, Boyle $P$ : Overview of the main outcomes in breast-cancer prevention trials. Lancet 2003, 36 I(9354):296-300.

9. Gronwald J, Tung N, Foulkes WD, Offit K, Gershoni R, Daly M, KimSing C, Olsson H, Ainsworth P, Eisen A, Saal H, Friedman E, Olopade O, Osborne M, Weitzel J, Lynch H, Ghadirian P, Lubinski J, Sun P, Narod SA: Tamoxifen and contralateral breast cancer in BRCAI and BRCA2 carriers: an update. Int J Cancer 2006, I | 8(9):228I -2284.

10. Rebbeck TR, Lynch HT, Neuhausen SL, Narod SA, Van't Veer L, Garber JE, Evans G, Isaacs C, Daly MB, Matloff E, Olopade OI, Weber BL: Prophylactic oophorectomy in carriers of BRCAI or BRCA2 mutations. N Engl J Med 2002, 346(2I): I6I6-1622.

II. Kauff ND, Satagopan JM, Robson ME, Scheuer L, Hensley M, Hudis CA, Ellis NA, Boyd J, Borgen PI, Barakat RR, Norton L, Castiel M, Nafa K, Offit K: Risk-reducing salpingo-oophorectomy in 
women with a BRCAI or BRCA2 mutation. N Engl J Med 2002, 346(2I): $1609-1615$

12. Rebbeck TR, Friebel T, Lynch HT, Neuhausen SL, van 't Veer L, Garber JE, Evans GR, Narod SA, Isaacs C, Matloff E, Daly MB, Olopade $\mathrm{OI}$, Weber $\mathrm{BL}$ : Bilateral prophylactic mastectomy reduces breast cancer risk in BRCA1 and BRCA2 mutation carriers: the PROSE Study Group. J Clin Oncol 2004, 22(6): 1055- 1062.

13. Domchek SM, Rebbeck TR: Prophylactic oophorectomy in women at increased cancer risk. Curr Opin Obstet Gynecol 2007, 19(I):27-30.

14. Easton DF, Ford D, Bishop DT: Breast and ovarian cancer incidence in BRCAI-mutation carriers. Breast Cancer Linkage Consortium. Am J Hum Genet 1995, 56(1):265-27I.

15. Schrag D, Kuntz KM, Garber JE, Weeks JC: Life expectancy gains from cancer prevention strategies for women with breast cancer and BRCAI or BRCA2 mutations. Jama 2000, 283(5):617-624.

16. Chang EI, Ly DP, Wey PD: Comparison of aesthetic breast reconstruction after skin-sparing or conventional mastectomy in patients receiving preoperative radiation therapy. Ann Plast Surg 2007, 59(I):78-8I.

17. Jugenburg M, Disa JJ, Pusic AL, Cordeiro PG: Impact of radiotherapy on breast reconstruction. Clin Plast Surg 2007, 34(I):29-37; abstract v-vi.

18. Goldflam K, Hunt KK, Gershenwald JE, Singletary SE, Mirza N, Kuerer HM, Babiera GV, Ames FC, Ross MI, Feig BW, Sahin AA, Arun B, Meric-Bernstam F: Contralateral prophylactic mastectomy. Predictors of significant histologic findings. Cancer 2004, I0 I(9): | $977-1986$.

19. Chang DW, Reece GP, Wang B, Robb GL, Miller MJ, Evans GR, Langstein HN, Kroll SS: Effect of smoking on complications in patients undergoing free TRAM flap breast reconstruction. Plast Reconstr Surg 2000, 105(7):2374-2380.

20. Schmeler KM, Sun CC, Bodurka DC, White KG, Soliman PT, Uyei AR, Erlichman JL, Arun BK, Daniels MS, Rimes SA, Peterson SK, Slomovitz BM, Milam MR, Gershenson DM, Lu KH: Prophylactic bilateral salpingo-oophorectomy compared with surveillance in women with BRCA mutations. Obstet Gynecol 2006, I08(3 Pt I):515-520.

\section{Pre-publication history}

The pre-publication history for this paper can be accessed here:

http://www.biomedcentral.com/1471-2407/8/101/pre pub
Publish with Biomed Central and every scientist can read your work free of charge

"BioMed Central will be the most significant development for disseminating the results of biomedical research in our lifetime. "

Sir Paul Nurse, Cancer Research UK

Your research papers will be:

- available free of charge to the entire biomedical community

- peer reviewed and published immediately upon acceptance

- cited in PubMed and archived on PubMed Central

- yours - you keep the copyright
BioMedcentral 